Jurnal Pemberdayaan: Publikasi Hasil Pengabdian kepada Masyarakat

Vol. 2, No. 2, Agustus 2018, Hal. 187-194

ISSN: 2088 4559; e-ISSN: XXXX-XXXX

DOI:

\title{
MEMBANGUN KOTA SEHAT (HEALTHY CITY) MENUJU INDONESIA SEHAT BERKEMAJUAN
}

\author{
Surahma Asti Mulasari ${ }^{1}$ \\ Universitas Ahmad Dahlan Yogyakarta ${ }^{1}$ \\ Email : surahma.mulasari@ikm.uad.ac.id ${ }^{1}$
}

\begin{abstract}
ABSTRAK
Pembangunan kesehatan adalah upaya strategis untuk memenuhi kebutuhan dasar masyarakat. Diperlukan peningkatan kesadaran, kemauan, dan kemampuan hidup sehat bagi setiap orang. Pemerintah melalui Peraturan Bersama Mentri Dalam Negeri dan Mentri Kesehatan menetapkan pedoman penyelenggaraan Kabupaten/Kota Sehat. Permasalahan umum yang berkaitan dengan Kota Sehat adalah karena kurangnya sosialisasi dari pemerintah. Hal tersebut menyebabkan masyarakat tidak mengetahui program Kota Sehat yang sudah dicanangkan. Masalah umum lainnya adalah belum adanya kerjasama lintas sektor yang baik. Tidak semua kota terbentuk Forum Kota Sehat (FKS). Jika terbentuk, antara anggota pengurus sendiri juga belum ada keterpaduan dalam persepsi dan pelaksanaan kegiatan. Tujuan dari kegiatan ini adalah untuk meningkatkan pengetahuan tentang kota sehat, manfaat serta langkah-langkah apa saja yang dapat dilakukan untuk menjadi kawasan pemukiman, sarana, dan prasarana umum yang sehat. Metode yang digunakan adalah melalui ceramah (talkshow), tanya jawab serta diskusi permasalahan tentang kota sehat. Sasaran pengabdian yaitu mahasiswa Fakultas Kesehatan Masyarakat Universitas Ahmad Dahlan dan masyarakat umum yang memiliki respon baik terhadap program yang sudah dilaksanakan. Pada saat kegiatan pengabdian dilasanakan, tamu undangan hadir dan berpartisipasi aktif selama proses talkshow berlangsung.
\end{abstract}

Kata Kunci: Kota Sehat, Pendidikan Kesehatan

\begin{abstract}
Health development was a strategic effort to meet the basic needs of the community. In order to achieve this, it can be through increasing awareness, willingness, and the ability to live healthy for everyone. Government through the Joint Minister of Home Affairs Regulation and Minister of Health establishes guidelines for the implementation of Healthy Districts / Cities. The general problem related to Healthy Cities was due to the lack of socialization from the government, causing the public not to know about the Healthy City program that has been proclaimed, even though the community has indirectly supported the program, including the Clean Friday activities. Another common problem was the lack of good cross-sector cooperation. Not all cities formed the Healthy City Forum (FKS). If formed, between the members of the board itself there was also no integration in the perception and implementation of the activities. The purpose of this activity was to increase knowledge about healthy cities, benefits and what steps can be taken to become healthy residential areas, facilities and infrastructure. The method used was through talkshow, question and answer and discussion of problems about healthy cities. The target of dedication, namely the Ahmad Dahlan University Public Health Faculty students and public, has a good response to the programs that have been implemented. When the service activities were held, invited guests attended and actively participated in the talkshow process.
\end{abstract}

Keywords: Healthy City, Health Education 


\section{PENDAHULUAN}

Dalam rangka meningkatkan derajat kesehatan masyarakat yang optimal maka pembangunan kesehatan adalah upaya strategis untuk memenuhi kebutuhan dasar masyarakat. Agar mencapai hal tersebut, dapat melalui peningkatan kesadaran, kemauan, dan kemampuan hidup sehat bagi setiap orang. Bidang kesehatan sebagai pendekatan yang dianggap paling tepat saat ini. Terkait hal tersebut pemerintah melalui Peraturan Bersama Mentri Dalam Negeri dan Mentri Kesehatan No.34 Tahun 2005 dan No. 1138/Menkes/PB/VII/2005 menetapkan pedoman penyelenggaraan Kabupaten/Kota Sehat.

Kota sehat adalah suatu kondisi kota yang bersih, nyaman, aman dan sehat untuk dihuni penduduk. Penyelenggaraannya dicapai melalui penerapan beberapa tatanan dengan kegiatan yang terintegrasi yang disepakati masyarakat dan pemerintah daerah. Penyelenggaraan Kota Sehat adalah berbagai kegiatan untuk mewujudkan Kota Sehat, melalui pemberdayaan masyarakat, dan forum yang difasilitasi oleh pemerintah kota. Forum adalah wadah bagi masyarakat untuk menyalurkan aspirasinya dan berpartisipasi. Forum Kota Sehat berperan untuk menentukan arah, prioritas, perencanaan pembagunan wilayahnya yang mengintegrasikan berbagai aspek, sehingga dapat mewujudkan wilayah yag bersih, nyaman, aman dan sehat untuk dihuni oleh wargaya.

Dalam pertemuan Walikota dan Bupati seluruh Indonesia pada tanggal 26-28 Juli 2000, disepakati untuk mengembagkan Kabupaten/Kota Sehat atas dasar komitmen Walikota/Bupati dan DPRD guna mendukung pembagunan berwawasan kesehatan menuju Indonesia Sehat 2010. Forum adalah wadah bagi masyarakat untuk menyalurkan aspirasinya dan berpartisipasi. Di Kab/Kota disebut forum Kab/Kota sehat atau namalain yang disepakati masyarakat. Forum tersebut seharusnya melibatkan semua instansi, termasuk swasta dan LSM yang ada beserta masyarakat. Untuk melibatkan masyarakat harapannya forum tersebut terbentuk mulai dari tingkat atas (Kota) sampai tingkat bawah yang berbentuk Kerja (Pokja). Dengan demikian upaya meningkatkan kesehatan merupakan tanggungjawab semua sektor, masyarakat, dan swasta.

Hapsari (2007) mengatakan bahwa permasalahan umum yang berkaitan dengan Kota Sehat adalah karena kurangnya sosialisasi dari pemerintah, menyebabkan masyarakat tidak mengetahui program Kota Sehat yang sudah dicanangkan, walaupun masyarakat secara tidak langsung telah mendukung program tersebut antara lain dengan kegiatan Jumat Bersih. Masalah umum lainnya adalah belum adanya kerjasama lintas sektor yang baik. Tidak semua kota terbentuk Forum Kota Sehat (FKS). Jika terbentuk, antara anggota pengurus sendiri juga 
belum ada keterpaduan dalam persepsi dan pelaksanaan kegiatan. Masih banyak anggota FKS yang berpikir bahwa FKS ini merupakan tugas Dinas Kesehatan saja. Sehingga programprogram FKS juga belum sepenuhnya dilaksanakan. Pelaksanaan program FKS sendiri masih terfokus pada upaya kuratif daripada promotif dan preventif.

Tatanan Kota Sehat dikelompokkan berdasarkan, kawasan dan permasalahan khusus yang terdiri dari: 1) kawasan permukiman, sarana, dan prasarana umum; 2) kawasan sarana lalu lintas tertib dan pelayanan trasportasi; 3) kawasan pertambangan sehat; 4) kawasan hutan sehat; 5) kawasan industri dan perkantoran sehat; 6) kawasan pariwisata sehat; 7) ketahaan pangan dan gizi; 8) kehidupan masyarakat sehat yang mandiri; 9) kehidupan sosial yang sehat. Dalam hal ini FKM memiliki peranan yang penting dalam mewujudkan kota sehat, terlebih sasaran untuk mewujudkan kota sehat adalah masyarakat itu sendiri.

Dari kesembilan Tatanan Kota Sehat tersebut, Kawasan Pemukiman, Sarana, dan Prasarana Umum merupakan tatanan yang sangat penting, mengingat di Yogyakarta sekarang mulai pemukiman mulai padat. Hal ini tercermin dari lahan yang kurang, banyaknya masyarakat luar kota yang sekarang tinggal di Yogyakarta. Tujuan dari kegiatan ini adalah untuk meningkatkan pengetahuan tentang kota sehat, manfaat serta langkah-langkah apa saja yang dapat dilakukan untuk menjadi kawasan pemukiman, sarana, dan prasarana umum yang sehat.

\section{METODE}

Metode yang diterapkan dalam program kegiatan pengabdian masyarakat ini adalah dengan metode ceramah yakni berupa kegiatan talkshow, diskusi dan tanya jawab. Materi yang disajikan berkaitan dengan kota sehat, yaitu meliputi definisi, ciri-ciri, tujuan, tatana dan strategi menuju kota sehat. Kegiatan pengabdian dilakukan bersama dengan mahasiswa FKM UAD yang berjumlah 7 mahasiswa. Kegiatan dilaksanakan pada hari Sabtu-Ahad, 10-11 November 2018 pada pukul 08.30-11.30 WIB. Sasaran kegiatan pengabdian ini adalah mahasiswa Fakultas Kesehatan Masyarakat Universitas Ahmad Dahlan dan masyarakat umum sebanyak 50 orang.

\section{HASIL, PEMBAHASAN, DAN DAMPAK}

Kegiatan pengabdian telah berjalan dengan baik dan lancar. Sasaran pengabdian yaitu mahasiswa Fakultas Kesehatan Masyarakat Universitas Ahmad Dahlan dan masyarakat umum yang memiliki respon yang baik terhadap program yang sudah dilaksanakan. Pada saat Membangun Kota Sehat (Healthy City) Menuju Indonesia Sehat Berkemajuan (Surahma Asti Mulasari) | 189 
kegiatan pengabdian dilasanakan, tamu undangan hadir dan berpartisipasi aktif selama proses talkshow berlangsung.

Pada dasarnya penyuluhan kesehatan identik dengan pendidikan kesehatan karena keduanya berorientasi terhadap perubahan perilaku yang diharapkan yaitu perilaku sehat. Sehingga mempunyai kemampuan mengenali masalah kesehatan dirinya, keluarga, dan kelompok dalam meningkatkan kesehatannya. Metode yang dapat digunakan dalam memberikan penyuluhan kesehatan yaitu dengan metode ceramah. Metode ceramah adalah suatu cara dalam menerangkan dan menjelaskan suatu ide, pengertian atau pesan secara lisan kepada sekelompok sasaran sehingga memperoleh informasi mengenai kesehatan (Notoatmodjo, 2010).

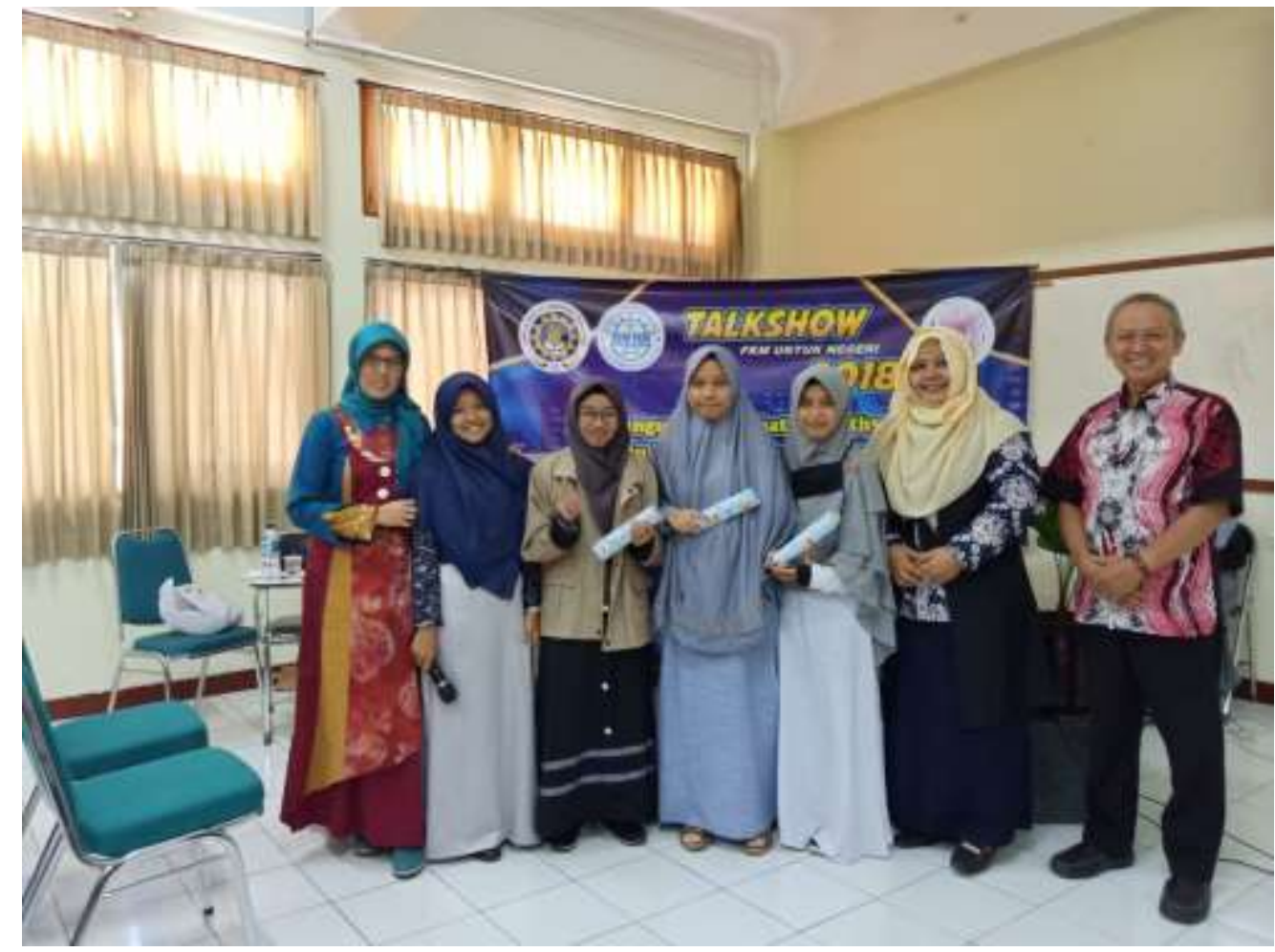

Gambar 1. Penyerahan Hadiah kepada Peserta

Dalam pelaksanaan kegiatan talkshow, peserta memberikan respon yang positif, mereka terlihat sangat antusias dengan kegiatan talkshow ini karena kegiatan ini dapat menambah wawasan peserta khususnya tentang pengertian kota sehat, ciri-ciri kota sehat, tatanan kota sehat, strategi menuju kota sehat dan lan sebagainya. Hal ini dapat dilihat bahwa pada saat kegiatan talkshow berlangsung komunikasi dua arah, peserta aktif dalam bertanya tentang hal-hal yang mereka ingin tahu. Peserta dan narasumber saling berdiskusi mengenai 
permasalahan-permasalahan yang terjadi saat ini. Diharapkan dengan adanya respon yang positif ini, peserta dapat menerapkan ilmu yang mereka peroleh serta dapat berpartisipasi dalam mewujudkan kota sehat.

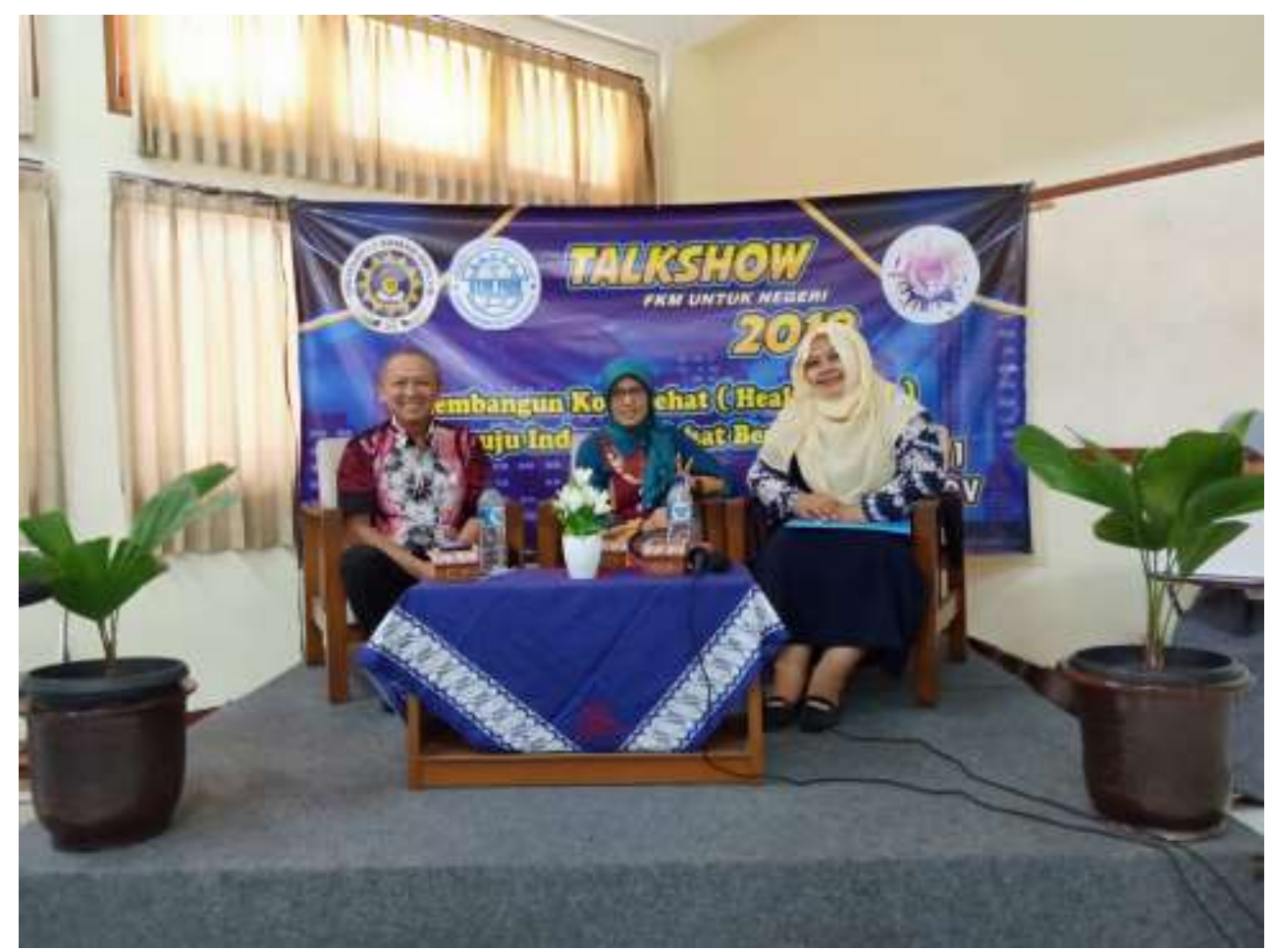

Gambar 2. Narasumber pada Kegiatan Talkshow

Nuraeni dkk. (2017) mengatakan bahwa sikap merupakan faktor yang mempengaruhi seseorang dalam melakukan suatu tindakan atau perilaku. Salah satu faktor yag mempengaruhi sikap seseorang adalah pendidikan, pengetahuan dan pengalaman. Untuk mendapatkan perilaku yag baik, maka faktor-faktor yang mempengaruhinya juga harus baik.

Kegiatan talkshow mengenai kota sehat ini merupakan salah satu kegiatan promosi kesehatan, yang merupakan proses memberikan kemampuan pada masyarakat dalam hal ini adalah peserta, untuk meningkatkan dan memperbaiki kesehatan khususnya mengenai program kota sehat. Saat ini, banyak masyarakat yang belum mengetahui mengenai salah satu program pemerintah yaitu program kota sehat ini. Oleh karena itu, diperlukan suatu informasi dan edukasi mengenai program kota sehat kepada seluruh masyarakat. Dengan diselenggaranya talkshow tentang kota sehat ini, sudah membantu pemerintah dalam menjalankan programnya. Karena pada dasarnya, penyelenggaraan kota sehat adalah melalui pemberdayaan masyarakat yang difasilitasi oleh pemerintah. 
Hapsari dkk. (2007) mengatakan bahwa perkembangan gerakan kota sehat di setiap negara berbeda satu sama lain, tergatung permasalahan yang dihadapi dan tidak dapat diperbandingkan. Kesamaan konsep kota sehat di seluruh negara satu sama lain berasal dari keinginan dan kebutuhan masyarakat, dikelola oleh masyarakat dan pemerintah berperan sebagai fasilitator.

Hapsari dkk. (2007) mengatakan bahwa permasalahan umum yang berkaitan dengan kota sehat adalah karena kurangnya sosialisasi dari pemerintah, maka menyebabkan masyarakat tidak mengetahui program Kota Sehat yang telah dicanangkan. Masalah lainnya adalah belum adanya kerjasama lintas sektor yang baik. Tidak semua kota terbentuk Forum Kota Sehat (FKS), jika terbentuk, antara anggota pengurus sendiri juga belum ada keterpaduan dalam persepsi dan pelaksanaan kegiatan.

Upaya-upaya untuk meningkatkan pengetahuan dan kesadaran untuk berpartisipasi mewujudkan kota sehat masih perlu dilakukan. Kegiatan talkshow sebagai salah satu media pembelajaran seperti ini perlu dilakukan secara rutin agar literasi kesehatan masyarakat dapat meningkat. Dengan adanya talkshow ini, diharapkan dapat meningkatkan pengetahuan dan kesadaran peserta dalam melakukan kegiatan yang berhubungan dengan kota sehat atau ikut serta menjalankan program pemerintah untuk mewujudkan kota sehat menuju Indonesia sehat yang berkemajuan.

\section{SIMPULAN}

Pelaksanaan kegiatan pengabdian telah berjalan dengan lancar. Intervensi dilakukan dengan metode ceramah, diskusi dan taya jawab yakni berupa kegiatan talkshow kepada peserta Fakultas Keseqhatan Masyarakat Universitas Ahmad Dahlan berjumlah 50 peserta terkait prioritas masalah yang ada, yaitu membangun Kota Sehat Menuju Indonesia Sehat Berkemajuan. Dalam pelaksanaan talkshow peserta berperan aktif dengan melakukan tanya jawab dan diskusi mengenai permasalahan yang terjadi saat ini berkaitan dengan program kota sehat. Adanya kegiatan talkshow ini dapat menjadi media promosi kesehatan yang diharapkan dapat berdampak pada peningkatan pengetahuan dan kesadaran peserta untuk mewujudkan kota sehat menuju Indonesia sehat berkemajuan. 


\section{DAFTAR PUSTAKA}

Departemen Kesehatan. (2004). Pedoman Kabupaten/Kota Sehat Bidang Kesehatan. Jakarta: Departemen Kesehatan

Hapsari, D., Sari, P., Afifah, T., Suriani, O., (2007). Gambaran Kebijakan Penyelenggaraan Kota Sehat pada Lima Kota di Indonesia. Media Litbang Kesehatan, Volume XVII Nomor 3. Halaman 19-28.

Notoatmodjo S. (2010). Ilmu Perilaku Kesehatan. Jakarta: PT Rineka Cipta.

Nuraeni, A., Mirwanti R., Anastasia A. (2017). Upaya Penegahan dan Perawatan Hipertensi di Rumah Melalui Media Pembelajaran Bagi Masyarakat di Kabupaten Pangandaran. Jurnal Pengabdian Kepada Masyarakat., 1(3), halaman 174-178.

Peraturan Perundangan, (2005), menetapkan pedoman penyelenggaraan Kabupaten/Kota Sehat, Peraturan Bersama Mentri Dalam Negeri dan Mentri Kesehatan No.34 Tahun 2005 dan No. 1138/Menkes/PB/VII/2005. 
